\title{
Study on the Inheritance and Development of the Art of Paper-cut in Henan Province
}

\author{
Chunsheng Xing \\ Arts and Design School \\ Huanghe Science and Technology College \\ Zhengzhou, Henan, 450005 \\ e-mail:11781899@qq.com
}

\begin{abstract}
Paper-cut is one of the popular folk arts in early China, which has lasted for thousands of years. It is the representation of the profound and grand Chinese national culture. Located in the central plains, Henan folk paper-cut is the important part of Chinese folk art, as well as the ancient visual symbol created by the hands and hearts of people in ancient central plains. Along with the changing of times, the art form of paper-cut is evolving gradually, for example, the form of expression and the cutting methods have changed dramatically. On surface, this form of art is disappearing, but the fact is that there are subtle changes in the development perspective and depth of paper-cut. How to inherit and develop Henan folk paper-cut is the essential part of the overall development of the central plains art forms, and the necessary means of promoting traditional culture, stimulating local economy and constructing Central Plain Economic Zone.
\end{abstract}

Keywords-Henan Province; Folk Paper-cut Art; Inheritance and Development

Paper-cut is also called paper carving, window decoration or picture cutting. Paper-cut is the embodiment of hollow-out art, providing the feeling and artistic enjoyment of hollow-out to people visually. Paper-cut is the most common and popular representation of folk art. With a scissor and a piece of paper, cutting the paper is the expression of sincere feelings and the earnest hope of the common people. It is not only the important means of beautifying the environment and dressing the life for the people, but also the direct way to express their ideals and think of the future.

There is a long history for Chinese folk paper-cut art, which can be traced backed to 6th century. Paper-cut has distinctive regional quality. Special historical period, culture, economy, social dynamics and other factors all influenced the style and appearance of paper-cut.

Located in the central plains, Henan has a vast area. The profound culture of the Yellow River area is fully represented in paper-cut. On this ancient Yellow land, our ancestors have created a group of splendid prehistoric culture that amazed the world, such as Yangshao Culture, Peiligang Culture and so on. During the five thousands of years history of Henan, from the first dynasty-Xia dynasty established its capital in Yanshi Henan to the destruction of the Qing Dynasty, more than 20 dynasties have established or moved their capitals to Henan. For example, Luoyang---ancient capital for nine dynasties, and
Kaifeng---ancient capital for eight dynasties all have displayed bright glory in the cultural progress of Chinese civilization. Paper-cut is one of the representatives.

Henan paper-cut has a long history. In Zhou Mi's "Zhi Ya Tang Duo Chao" in the Southern Song Dynasty, there was the description of the pomp of selling paper-cut in Kaifeng city, "On the street of the capital in the past, there are people who do paper-cut... A young man can cut characters and flowers in his sleeves, whom is very famous at that moment." From the description, we can see that paper-cut was relatively widely spread in the society in the Song Dynasty. There were the paper-cut artists who made living by selling paper-cut, and their skills have reached a very high artistic level.

The art form of paper-cut in Henan province can be divided into two schools, namely Yudong School (East part of Henan) and Yuxi School (West part of Henan). Yuxi School is mainly traditional folk paper-cut, while Yudong School reflects the local customs. As the origination place of the central plains civilization, the art of paper-cut in Henan is more prominent than any other type of art in the width of spread, the number of quantity, the variety of form and the depth of foundation. From the artistic style, Henan paper-cut has distinct characteristics of the central plains culture. Simple, profound, rich and contrastive are the artistic style of Henan paper-cut. Folk paper-cut in the west of Henan province is the major representative of Henan paper-cut. It has a long history, broad range of topics, rich interests, fine cutting skills and numerous works. With a strong local flavor, it has formed its special artistic style.

Since the come into being of Henan folk paper-cut, it has never been interrupted. Among all kinds of folk activities, paper-cut has arouse people's pursuit to life, faith to lives and hope for a rich country and healthy people in its own special manner quietly. However, because of all kinds of history prejudices and many other special reasons, this kind of folk art has not been placed in the equal place with other forms of art. Paper-cut was usually handed down from generation to generation in a very fragile manner simply depends on oral teaching and personal understanding. Once there is no inheritor, it would disappear and vanish quickly like a kite without a string. Therefore, the mode of existence for papercut was running its own course. In the industrialization and globalization today, paper-cut is surely confronted with 
decisive blows. Along with the acceleration of industrialization and urbanization, all kinds of folk arts in the decline are the first to be affected. The further development of market economy is a golden opportunity of to prosper and develop for Henan paper-cut. However, as for the present developing situation, Henan paper-cut has been forced into a situation that must begin all over again. The social public, including the local government all lack the preservation, excavation and inheritance of the art of paper-cut, thus cause a temporary shortage for paper-cut. Some unique skills of papercut are in their critical moment. Some types of paper-cut have disappeared in the market, and need recompile to restore. The reserve personnel of paper-cut are short and the paper-cut artists have been affected greatly by the market.

Along with the continuous development of social economy, most folk arts have been affected greatly, and the art of papercut is no exception. Under such situation, how to preserve the art of paper-cut? First, it should develop with the times to achieve new development and innovation, so as to adapt to the present aesthetic standards and actual needs. The second problem is how to adapt to the development of the market for the folk arts. It is because that within the present economic trend, only if one enters into the market can it find the new way out. As refer to Henan paper-cut art, I personally think that it should go out of the small yard of the farmers, and enter into the wide world of modern art. On the one hand, the beauty of paper-cut can be displayed in different aspects like packing design, cloth design, decoration design, stage art, animation, film and so on, making it famous throughout the world and become the cultural and artistic treasure of human. On the other hand, it is very important to enter into the market and form scale effects. Cooperation with the business is to make folk art works develop into mass production and industrialization from small folk workshop. The participation of business not only provide large amount of fund for the development of folk art, but more importantly inject new blood to folk artistic work on management and the concept of promotion. At the same time, cultural industries also establish their own personnel training base to cultivate and train the talents on different fields, and thus promote the development of talents.

\section{PAPER-CUT IS A KIND OF FOLK ART ORIGINATED FROM DAILY LIFE}

Only when it is well lead and deeply excavated can promote the industrialized development and achieve the goal of enriching the people. There is a strong trend for the development of Henan folk paper-cut, mainly represented in the following aspects.

\section{A. Small Window Decoration Walks into the World}

Generations of folk artists have promoted $\mathrm{Yu}$ county paper-cut to be mature from draft creation, and from single color to multi color. They also created the unique techniques of adding details to the paintings of paper-cut and started paper-cut of several pieces of paper to reflect new realism. A small window decoration is the accumulation of several kinds of folk arts, and the representation of Chinese civilization. Because of the progress of paper-cut techniques, the contents of paper-cut almost cover and contain everything, such as fish, insects, and human figures and so on. At the same time, papercut should be combined with fashion, and cover fashion elements into the works to represent the international qualities.

\section{B. Litter Paper-cut Creates a Big Brand}

Brand is the reflection of the comprehensive qualities of paper-cut industry, as well as the invisible productive power. Yu County held on the brand strategy and actively started declaration and participated in different kinds of activities. It has realized the historical step from national intangible cultural heritage to world intangible cultural heritage, receiving unprecedented glory and award.

\section{Small Workshop Creates the Big Market}

The vitality of paper-cut art has its root in the public. Only by arousing the people's passion of starting a business and creation can meet the growing needs of the cultural market.

\section{Small Work Conveys Deep Meaning}

Innovation is the soul of national progress and the inexhaustible vitality of inheriting art.

\section{E. Small Products Make a Big Business}

The best way to inherit and carry forward the art of papercut is to enter into the market to realize its values and promote industrialized development.

\section{F. Small Promotion Produces Big Influence}

The best way of promotion is not just big investment, paper-cut should develop by the special ways of "small scale but high standard, low cost but grand influence" based on the actual situation. At present, the most popular ways of promotion is to invest a large amount of money to do many advertisements in print medias, network medias and China Central Television, producing sensational effects and improving the popularity and influence. For example, Liaocheng in Shandong province, Lijiang in Yunnan province, Jiaozuo Yuntai Mountain in Henan province, Music Ritual of Shaolin Temple in Dengfeng, Dreamlike Glory in Kaifeng--ancient capital of eight capitals, etc. all employed this manner.

\section{IN ORDER TO PRESERVE, DEVELOP AND STRENGTHEN THE PAPER-CUT INDUSTRY IN HENAN PROVINCE}

we should continue digging the cultural connotation to promote the industry, and adding charm to it to expand the market, thus built the last paper-cut tribe in the world and the cultural brand of Chinese nation. Following are some patters for the specific development.

\section{A. Start a Group Corporation to Improve the Key Competitiveness}

We should make industry criterion and strengthen industry management. Consolidating and improving to build the distributing center of paper-cut business in the country and in the world. Formulating norms on techniques and improving the techniques level to form an operating mode which involves 
creation, cutting paper, advertising and promotion, direct marketing and online marketing. And we also need to promote scale development and intensive development, change the disorder competition such as working on one's own, grabbing each other's market, price disorder, and product assimilation.

\section{B. Wide Communication to Enhance Market Interaction}

We should collect the works from different paper-cut inheriting places widely, hold China paper-cut competition at regular intervals, and perfect the beneficial policies to attract more business. And also play the role of Chinese Paper-cut Association and hold high level forum on paper-cut nationally and internationally, promote the study of paper-cut theory through thesis and organizing seminars. Meanwhile, we should start a national paper-cut website to construct a communication platform where all schools of thoughts could contend with each other for experts who study on the research of traditional culture, scholars, amateurs, and paper-cut artists to encourage their views on paper-cut.

\section{Deepen Creativity to Active Paper-cut}

There is no boundary for culture, and no limitation for creativity. We should rely on Chinese Paper-cut Art Institute and unite Henan paper-cut industries to establish the design center or workshop, making overall innovation on techniques, function and materials of paper-cut to improve the market share in a large scale. The first thing is to promote the innovation of making techniques. On the one hand, introducing high tech manners like computer design, painting and machine manufacturing to produce paper-cut products that cost less time in large quantity and use only once, therefore enhance productivity. Another aspect is to improve the techniques of creation and learn from the paper-cut experience of new realism, and thus start the new paper-cut techniques. The second thing is to widen the field of function for paper-cut and develop into high level collection. This involves the making of large and high level paper-cu works mostly to make paper-cut become an important luxury decoration and precious collection. For example, railway platform tickets using $\mathrm{Yu}$ county paper-cut as the content is going to operating formally; develop in practical field, besides the making of small decorations like desk calendar, wall calendar and paper-cut decoration, extend paper-cut into the field of household decoration like glass paper-cut door and paper-cut wall paint, etc.; in fashion field, there are paper-cut wedding dress and character portraits; in the field of television, film and drama, producing paper-cut animation works to reflect local customs; in the field of intellectual development, making mould for children paper-cut to arouse their interest to make and think; expand the using by making paper-cut patterns on air tickets, bank receipts, and bank cards; improve the value the paper-cut by combining with national celebrities' inscriptions. The third thing is to realize the variety of materials, extend on the manufacture tools and materials, emphasize both on manual craftsmanship and modern techniques, both vegetable dyes and mineral dyes.

\section{Emphasize the Blending to Give Play to Regional Driving Force}

Base on digging the connotation of paper-cut, learn from others strong points to offset own weakness and from foreign countries and the ancient times, therefore build the cultural industry that has strong local characteristics. First, employ paper-cut into folk activities, for example, blend Yangko (a popular rural folk dance), Dashuhua, Baidengshan, Diangan and other folk culture with paper-cut. Second, inject paper-cut into travel industry as the symbol. Using paper-cut art and works in scenery construction, hotel decoration, logo, and travel products, etc. to improve the popularity of Henan papercut and enrich the connotation of travel. Third, using paper-cut in industrial production. Contain paper-cut culture in every part of industry management and production, especially the productions that contain paper-cut culture, such as paper-cut clothes, furniture, daily necessities, etc., thus create a special industry culture. Fourth is to display the beauty of paper-cut in the city construction, design architectures, sceneries, advertisements that contain the art of paper-cut to display the distinctive city culture.

\section{E. Emphasize Promotion to Enlarge World Influence}

Taking exhibitions as the important tool to promote the combination of exhibition and selling to improve the popularity. We can hold interaction paper-cut art festivals, establishing the platform for world paper-cut artists to communicate, thus promote paper-cut works that represent the region going to the world. At the same, we should actively build photography base and film base, hold paper-cut exhibition in art department in universities, national museums and UN, therefore further expand the influence and attraction of Henan paper-cut.

Along with the changing of times, traditional folk concept of Henan people is weakening gradually, instead the modern aesthetic needs. In the present rural areas in Henan, the farmers' spirits are brand new since they gradually get rid of the poor situation and become rich. They earnestly need new life style to meet their material and spiritual needs. As the crystallization of thousands of year's folk art, Henan folk paper-cut is not only the symbol of regional culture, but also the typical symbol of Chinese culture. The art of paper-cut have strong vitality. She has aroused people's pursuit to life and hope for real, kindness and beauty by her special way. The commonality of modern folk paper-cut has been improved greatly. Paper-cut cultural relics are the treasure of folk culture, the evidence of history and the memory of present life.

\section{ReferenceS}

[1] Xu Chunyan. Paper-cut in the West of Henan Province. Chinese Social Sciences Weekly. 2001.

[2] Feng Jicai, Ni Baocheng. Collection of China Folk Art---Column of the west Henan province.

[3] Zhu Xiaohong, appreciation and creation of Chinese Paper-cut Art. Publish House of Henan University. 2009

[4] Chen Jing. History of China Folk Paper-cut. Peking University Press. 2002 
[5] Wang Guisheng. Cultural Explanation of Paper-cut folk art. Peking University Press. 2010 